\title{
Therapeutic Potential of Polyphenols in Cardiac Fibrosis
}

\section{OPEN ACCESS}

Edited by:

Nicolau Beckmann,

Novartis Institutes for BioMedical

Research, Switzerland

Reviewed by:

Vicente Lahera,

Complutense University of Madrid

Spain

Robert Widdop

Monash University, Australia

Sandrine Horman,

Université Catholique de Louvain,

Belgium

Syvain Richard,

Université de Montpellier, France

*Correspondence:

Qi-Zhu Tang

qztang@whu.edu.cn

Specialty section:

This article was submitted to Cardiovascular and Smooth Muscle

Pharmacology,

a section of the journal

Frontiers in Pharmacology

Received: 26 October 2017

Accepted: 02 February 2018

Published: 15 February 2018

Citation:

Zhang N, Wei W-Y, Li L-L, Hu C and Tang Q-Z (2018) Therapeutic Potential

of Polyphenols in Cardiac Fibrosis.

Front. Pharmacol. 9:122

doi: 10.3389/fphar.2018.00122

\author{
Ning Zhang ${ }^{1,2,3}$, Wen-Ying Wei ${ }^{1,2.3}$, Ling-Li $\mathrm{Li}^{1,2,3}$, Can Hu ${ }^{1,2,3}$ and Qi-Zhu Tang ${ }^{1,2,3 *}$ \\ ${ }^{1}$ Department of Cardiology, Renmin Hospital of Wuhan University, Wuhan, China, ${ }^{2}$ Cardiovascular Research Institute of \\ Wuhan University, Wuhan, China, ${ }^{3}$ Hubei Key Laboratory of Cardiology, Wuhan, China
}

Cardiac fibrosis, in response to injury and stress, is central to a broad constellation of cardiovascular diseases. Fibrosis decreases myocardial wall compliance due to extracellular matrix (ECM) accumulation, leading to impaired systolic and diastolic function and causing arrhythmogenesis. Although some conventional drugs, such as $\beta$-blockers and renin-angiotensin-aldosterone system (RAAS) inhibitors, have been shown to alleviate cardiac fibrosis in clinical trials, these traditional therapies do not tend to target all the fibrosis-associated mechanisms, and do not hamper the progression of cardiac fibrosis in patients with heart failure. Polyphenols are present in vegetables, fruits, and beverages and had been proposed as attenuators of cardiac fibrosis in different models of cardiovascular diseases. Together with results found in the literature, we can show that some polyphenols exert anti-fibrotic and myocardial protective effects by mediating inflammation, oxidative stress, and fibrotic molecular signals. This review considers an overview of the mechanisms of cardiac fibrosis, illustrates their involvement in different animal models of cardiac fibrosis treated with some polyphenols and projects the future direction and therapeutic potential of polyphenols on cardiac fibrosis.

Keywords: cardiac fibrosis, polyphenols, anti-fibrotic, therapy, signaling pathway

\section{INTRODUCTION}

Cardiac fibrosis is a hallmark of numerous cardiovascular diseases including hypertension, myocardial infarction (MI), and ischemic, dilated, and hypertrophic cardiomyopathy. Cardiac fibrosis not only interferes with the systolic and diastolic functions and but is also the main determinant of malignant arrhythmias and consequently increases the risk of sudden cardiac death (Roche et al., 2015). There are two patterns of cardiac fibrosis presentation: regional fibrosis and diffuse fibrosis. Regional fibrosis mainly occurs in the healing infarcted ventricle following coronary occlusion, ultimately resulting in the formation of a collagen-based scar (Prabhu and Frangogiannis, 2016). On the other hand, diffuse fibrosis is associated with cardiac remodeling in the conditions of pressure and/or volume overload, metabolic disorder, or ischemic insults and is characterized by unbalanced collagen turnover and excessive diffuse collagen deposition in the interstitial spaces (Frangogiannis, 2017). Some fibrotic factors, such as cytokines, chemokines, growth factors, hormones, and reactive oxygen species (ROS), are responsible for the activation of fibroblasts and the alteration of extracellular matrix (ECM) (Heymans et al., 2015).

A constellation of mechanisms and signaling pathways have been involved in fibroblast activation and pathological remodeling. Mediation of these mechanisms and molecular signals have provoked an intense scientific interest as they work out a novel therapeutic strategy for cardiac fibrosis. At present, the inhibition of cardiac fibrosis and its adverse complications is 
mainly focused on the conventional drugs, including angiotensin-converting enzyme inhibitors (ACEI), aldosterone antagonists, $\beta$-blocker, and statins (Zannad et al., 2000; Bauersachs et al., 2001; Klapholz, 2009; Van de Werf, 2014). These interventions could result in a partial recovery of cardiac function; nevertheless, these effects are secondary to the correction of the underlying cardiac dysfunction mechanisms rather than alleviating fibrosis directly. Moreover, multiple lines of evidence have indicated that pirfenidone alleviates cardiac remodeling in hypertensive rats and pressure-overload in hypertrophic hearts (Mirkovic et al., 2002; Wang et al., 2013). Pirfenidone also decreased infarct scar and improved left ventricle function following cardiac infarction (Nguyen et al., 2010). The other anti-fibrotic drug currently approved for clinical treatment in human idiopathic pulmonary fibrosis (IPF) was nintedanib, just as with pirfenidone (Bando, 2016). Nintedanib is also the subject of ongoing clinical trials for systemic sclerosis. Although nintedanib and pirfenidone show promise for the alleviation of cardiac fibrosis, there are no clinical results to support that these drugs are specifically targeted to the intracellular mechanisms of fibrosis. Therefore, the urgent challenge we are confronting is to find novel potential agents to retard cardiac fibrosis.

Polyphenols are found in plant-derived foods and beverages. Collective evidence has indicated that natural polyphenols possess multiple protective effects against cardiovascular diseases (Raj et al., 2014; Niu et al., 2015). Additionally, polyphenols classified to different subclasses have been reported to alleviate cardiac dysfunction and fibrosis following cardiac injury. In this review, we will examine the role of associated mechanisms in the progression of cardiac fibrosis, illustrate their involvement in the current and emerging intervention of polyphenols, and identify the promising targets of polyphenols for basic and applied cardiac research.

\section{MOLECULAR MECHANISM AND SIGNALS ASSOCIATED WITH CARDIAC FIBROSIS}

Numerous molecular signals involved in the pathogenesis of cardiac fibrosis, and the identification of these molecular signals implicated with the initiation, progression, and regression of the fibrotic response will help us to effectually target the major culprit to retard cardiac fibrosis (Kong et al., 2014). Inflammatory signals could activate myofibroblasts and seem to play a vital role in regional and diffuse fibrosis. Oxidative stress manifested as an imbalance between a ROS generation and the capacity of anti-oxidant defense systems has been regarded as the most important mechanism in cardiac fibrosis. Other complex cellular mediators, including the transforming growth factor- $\beta$ (TGF$\beta)$, renin-angiotensin-aldosterone system (RAAS), and plateletderived growth factor (PDGF), also appear to be implicated in cardiac fibrosis. Therefore, intricate cellular and molecular mechanisms contribute to the pathogenesis of cardiac fibrosis (Figure 1).

\section{Inflammation in Cardiac Fibrosis}

The production of inflammatory signaling molecules during cardiac injury and hypertrophic remodeling can contribute to hypertrophic and fibrotic responses. Activated immune cells, including macrophages, monocytes, lymphocytes, and mast cells, are involved in orchestrating cardiac fibrosis, as reviewed by Ryan A. Frieler (Frieler and Mortensen, 2015). In a mouse model of cardiac infarction, pro-inflammatory cytokines, such as tumor necrosis factor- $\alpha$, interleukin-1 $\beta$ (IL-1 $\beta$ ), and IL- 6 released by infiltrated neutrophils and macrophages, could exert a significant role to induce the proliferation of resident fibroblasts and activate myofibroblasts, resulting in cardiac fibrosis (Christia et al., 2013). Moreover, activated cardiac fibroblasts (CFs) also generate numerous cytokines and growth factors that mediate ECM remodeling via autocrine and paracrine mechanisms. After acute cardiac insult, IL- $1 \beta$ enhances fibroblasts migration through the mitogen-activated protein kinase (MAPK) pathway (Mitchell et al., 2007), and IL-6 is known to promote fibroblast proliferation and aggravate myocardial fibrosis (Banerjee et al., 2009). The inflammatory response can also be regulated or induced by cardiac endothelial cells, which recruit macrophages and monocytes through the production of a wide range of cytokines and pro-fibrotic mediators, including TGF- $\beta$, fibroblasts growth factor, and endothelin-1 (Wynn, 2008). In humans, an increased level of stressed-induced cytokines, including TNF- $\alpha$, IL- 6 , and IL-1 $\beta$, correlates with a poor prognosis in patients with heart failure (Frieler and Mortensen, 2015). Extensive studies have indicated a significant role of inflammation in the fibrotic response, where the inhibition of inflammatory factors could provide an effective therapeutic strategy in the treatment of cardiac fibrosis.

\section{Oxidative Stress in Cardiac Fibrosis}

Clinical and experimental studies have indicated that oxidative stress, which is defined as the imbalance of excess ROS production and anti-oxidant defense, is enhanced in cardiac remodeling ( $\mathrm{Wu}$ et al., 2017b). In the cardiac tissues, ROS is mainly sourced from (i) the membrane-bound enzyme complex NADPH oxidase (NOX), (ii) the mitochondrial respiratory chain, and (iii) uncoupled endothelial nitric oxide (NO) synthase (eNOS). Moreover, ROS activates a wide range of hypertrophy signaling kinases and transcription factors and regulates apoptosis. ROS also enhance CF proliferation and stimulate the matrix metalloproteinases (MMPs), resulting in cardiac fibrosis (Tsutsui et al., 2011).

Recent studies demonstrated that NOXs, a family of enzymes implicated in the generation of ROS, are involved in myocardial fibrosis and heart failure progression (Heymans et al., 2015). All forms of NOX, NOX2, and NOX4 are predominantly expressed in the myocardium. In the pathological condition, the expression of NOX increases in the end-stage failing human heart, and cardiac hypertrophy appears as a marked source of increased cardiac ROS. Cardiac hypertrophy induced by Ang II is blunted in gp91 $91^{\text {phox }}$ deficient mice (Shanmugam et al., 2011); however, this protective effect in the deletion of gp91phox subunit in mice is abolished in pressure-overloadinduced cardiac hypertrophy (Maytin et al., 2004). In particular, 


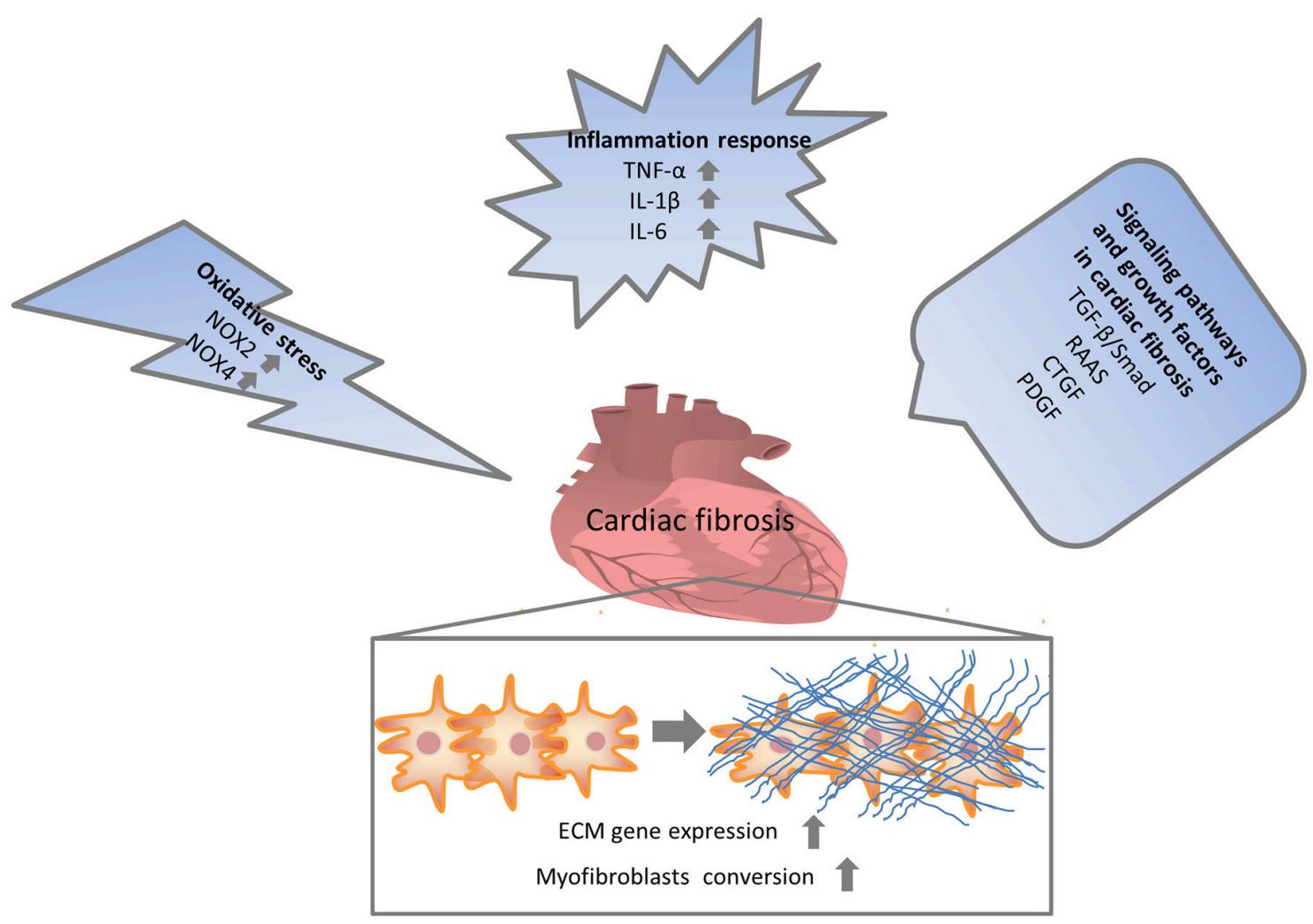

FIGURE 1 | Multiple mechanisms involved in cardiac fibrosis. Enormous initiating insults contributed to oxidative stress, inflammation and increased growth factors, which in turn directly or indirectly enhanced cardiac fibrosis. NOX, NAPDH oxidase; TNF, tumor necrosis factor; IL, interleukin; TGF, transforming growth factor; RAAS, renin-angiotensin-aldosterone system; CTGF, connective tissue growth factor; PDGF, platelet-derived growth factor.

NOX2 enhances myocardial fibrosis stimulated by TGF- $\beta$, Ang II stimulation in a rat (Johar et al., 2006; Miguel-Carrasco et al., 2012). Endothelial-specific overexpression of NOX2 promotes interstitial cardiac fibrosis via enhancement of the proinflammatory effect and endothelial-mesenchymal transition (Murdoch et al., 2014). Interestingly, eliminating NOX2-induced superoxide anions in CFs retards collagen generation (Lijnen et al., 2012). The previous study also found NOX4 mediates the TGF- $\beta$-stimulated conversion of CFs to myofibroblasts (Cucoranu et al., 2005). Collectively, NOX-mediated oxidative stress plays a significant role in the progression of myocardial fibrosis.

\section{Molecular Signaling Pathways Involved In Cardiac Fibrosis TGF- $\beta$ Signaling Pathway}

Three isoforms of TGF- $\beta$ (1, 2, and 3) exist in mammals, which are generated by fibroblasts, leukocytes and platelets. TGF$\beta$ is primarily produced as a secreted potent form, which is proteolytically activated in a pattern implicated in an integrinmediated ECM contraction (Sarrazy et al., 2014). The type I TGF- $\beta$ receptor, also termed activin receptor-like kinase (ALK) 5, predominantly participates in the fibrotic activities of TGF- $\beta$. The established pathway of TGF- $\beta 1$ involved in the activation of ALK5 subsequently phosphorylates Smad2/3; phosphorylated Smad2/3 combines with Smad 4 and translocates into the nucleus, where it finally induces the activation of enormous fibrotic genes. TGF- $\beta 1$ stimulates the collagen lattice contraction and the $\alpha$-SMA expression in a smad3-dependent fashion (Dobaczewski et al., 2010) Importantly, TGF- $\beta$ promotes the phenotype conversion of CFs to myofibroblasts and activates ECM component genes to encode fibrillar collagen (Dobaczewski et al., 2011). To inhibit the detrimental effect of TGF- $\beta 1$ in cardiac remodeling, the ALK inhibitor SM16 is utilized to blunt the TGF- $\beta$-induced collagen I $\alpha 2$ and the lysyl oxidase expression in vitro, where it mitigates the cardiac fibrosis in the model of pressure overload (Engebretsen et al., 2014). Moreover, neutralizing anti-TGF- $\beta$ antibodies decreases the collagen mRNA expression and inhibits fibroblast activation in a rat model of pressure overload (Kuwahara et al., 2002). In addition to the canonical pathway, TGF- $\beta$ also activates a non-canonical signaling pathway that is implicated in several downstream MAPKs, including c-Jun N-terminal kinase (JNK), P38, and TGF- $\beta$-activated kinase 1 (TAK1) (Yan et al., 2009). Each of these MAPKs phosphorylates numerous transcription factors mediate the expression of $\alpha$-SMA, ECM proteins, and other target genes implicated in cardiac fibrosis. Collectively, the data indicate that the blocking of the downstream TGF- $\beta$ 
signaling pathway could be one viable option for anti-fibrotic therapy.

\section{Renin-Angiotensin-Aldosterone System (RAAS)}

Comprehensive studies indicate that RAAS activation is consistently detected in fibrotic hearts regardless of etiology. Angiotensin II (Ang II) plays a predominant role in the development of cardiac fibrosis (Kong et al., 2014). In vitro, Ang II enhances fibroblast proliferation and migration and induces ECM protein synthesis through the activation of the Ang II type I receptor (AT1R) (Sadoshima and Izumo, 1993; Chen X. Q. et al., 2015). In contrast, AT2R could retard fibroblast proliferation and matrix deposition and work as a negative mediator of the Ang II-induced fibrotic response (Ma et al., 2012). It is also reported that Ang II participates in the TGF- $\beta$ signaling pathway in CFs (Schultz Jel et al., 2002). Furthermore, activation of AT1R stimulated by Ang II promotes the expression of TGF- $\beta 1$ and suggests that Ang II enhances the pathological role of TGF- $\beta 1$ in inducing cardiac hypertrophy and fibrosis (Schultz Jel et al., 2002). Moreover, collagen expression of fibroblasts induced by AngII requires the activation of the TGF- $\beta /$ Smad and MAPK signaling pathway. Collectively, Ang II signaling can induce myofibroblast differentiation through enhancement of TGF- $\beta 1$ expression and the activation of canonical and non-canonical signaling effectors, and/or directly activating MAPK-serum response factor (SRF) signaling (Davis and Molkentin, 2014).

\section{Connective Tissue Growth Factor (CTGF)}

CTGF, also known as CNN2, is significantly upregulated in human heart failure and the myocardial fibrosis associated animal model (Chuva de Sousa Lopes et al., 2004; Koshman et al., 2013). Factors including TGF- $\beta$, Ang II, ET-1, and mechanical stress can induce the expression of CTGF in cardiomyocytes and fibroblasts (Travers et al., 2016). Intriguingly, the expression of CTGF is increased before the upregulation of TGF- $\beta$, suggesting an important role in cardiac fibrosis. Surprisingly, there is neither a gain nor a loss of CTGF in the cardiac tissue influencing cardiac function and fibrogenesis. Moreover, mediation of CTGF slightly affects the response to TGF- $\beta$ in pressure-overload-induced heart failure. The data above suggest that CTGF is less important as a TGF- $\beta$ effector and to elucidate the potential role in cardiac fibrosis.

\section{Platelet-Derived Growth Factor (PDGF)}

PDGF has been involved in the progression of cardiac fibrosis by inducing the synthesis of TGF- $\beta$. However, TGF$\beta$ could also enhance the production of PDGF (CzuwaraLadykowska et al., 2001; Zhao et al., 2013). Following MI, PDGF contributes to collagen accumulation, fibroblast proliferation, and enhances scar reparation (Al Hattab and Czubryt, 2017). Cardiac-specific overexpression of PDGF markedly increases the expression of TGF- $\beta 1$ and contributes to the development of cardiac fibrosis (Tuuminen et al., 2009). These results indicate that PDGF plays a potential role in cardiac fibrosis and appears to be suggesting a potential target for anti-fibrotic therapy.

\section{ANTI-FIBROTIC EFFECT OF POLYPHENOLS ON CARDIAC FIBROSIS}

Polyphenols contain several phytochemicals sharing a common phenolic structure, and they are divided into flavonoids and nonflavonoids (Del Rio et al., 2013). Flavonoids are formed by 15 carbons with two aromatic rings connected by a three-carbon bridge, indicated as C6-C3-C6. The main subclasses of flavonoids are divided into flavones, isoflavones, flavonols, flavan-3-ols, flavanones, and anthocyanidins. Non-flavoniods do not possess the C6-C3-C6 structure and could formed by a single phenolic ring combined to one or three carbons such in phenolic acids or hydroxycinnamic acids; another representative non-flavonoids is still benes with a C6-C2-C6 stricture such as resveratrol (Salomone et al., 2016). Some polyphenols are characterized by the inhibition of cardiac fibrosis (Jiang et al., 2010). In this section, we aimed to summarize the existing experimental evidence regarding polyphenols and cardiac fibrosis (Table 1).

\section{Flavonols and Flavan-3-Ols in Cardiac Fibrosis}

Quercetin, one of the most widely distributed flavonols, is abundant in red onions, citrus fruits, grains, and many other foods of plant origin (Pawlikowska-Pawlega et al., 2003). The quercetin found in dietary bioflavonoids coexists with its glycoside derivative, rutin. Studies have demonstrated that rutin was more soluble than quercetin. In the animal model of cardiac fibrosis, the administration of quercetin and rutin or single quercetin attenuated cardiac dysfunction and myocardial injury stimulated by isoproterenol (ISO) and prevented cardiac fibrosis by inhibition of CTGF, TGF- $\beta 1$, and ECM deposition (Li et al., 2013). Panchal et al. indicated that in a model of an obese rat being fed a western diet supplemented with quercetin, cardiac remodeling was prevented via the inhibition of the NF- $\kappa \mathrm{B}$ signaling pathway and the promotion of the nuclear factor erythroid 2-related factor 2 (Nrf-2) and its downstream molecules (Panchal et al., 2012). Taxifolin, one of quercetin derivatives, has the ability to blunt cardiac fibrosis induced by pressure overload, the mechanism underlying anti-fibrotic effect of taxifolin dependents on inhibition of TGF- $\beta / \mathrm{Smad}$ signaling pathway (Guo et al., 2015). Isorhamnetin, another ingredient of flavonols, ameliorates cardiac hypertrophy and fibrosis induced by aortic banding (Gao et al., 2017). Consistent with the results above, Boerhavia diffusa extracted with ethanol (BDE) is a rich source of bioactive flavonols containing quercetin, boeravinone, kaempferol, and caffeic acid, mitigating Ang IIinduced cardiac fibrosis via the inhibition of TGF- $\beta 1$ expression and collagen deposition (Prathapan et al., 2017). In recent years, the metabolic effect of rutin and troxerutin have been examined in robust animal models of metabolic syndrome. Anuradha et al. demonstrated that troxerutin enhances insulin sensitivity, reduces lipid accumulation and upregulates fatty acid oxidation in the heart (Geetha et al., 2014); furthermore, troxerutin slowed the fibrotic response in the myocardium following the long-term feeding of a high-fat high-fructose diet (Geetha et al., 2015).

The beneficial effect of green tea has been attributed to the presence of abundant catechins. Epigallocatechin-3-gallate (EGCG) is the most abundant and powerful catechin in green 


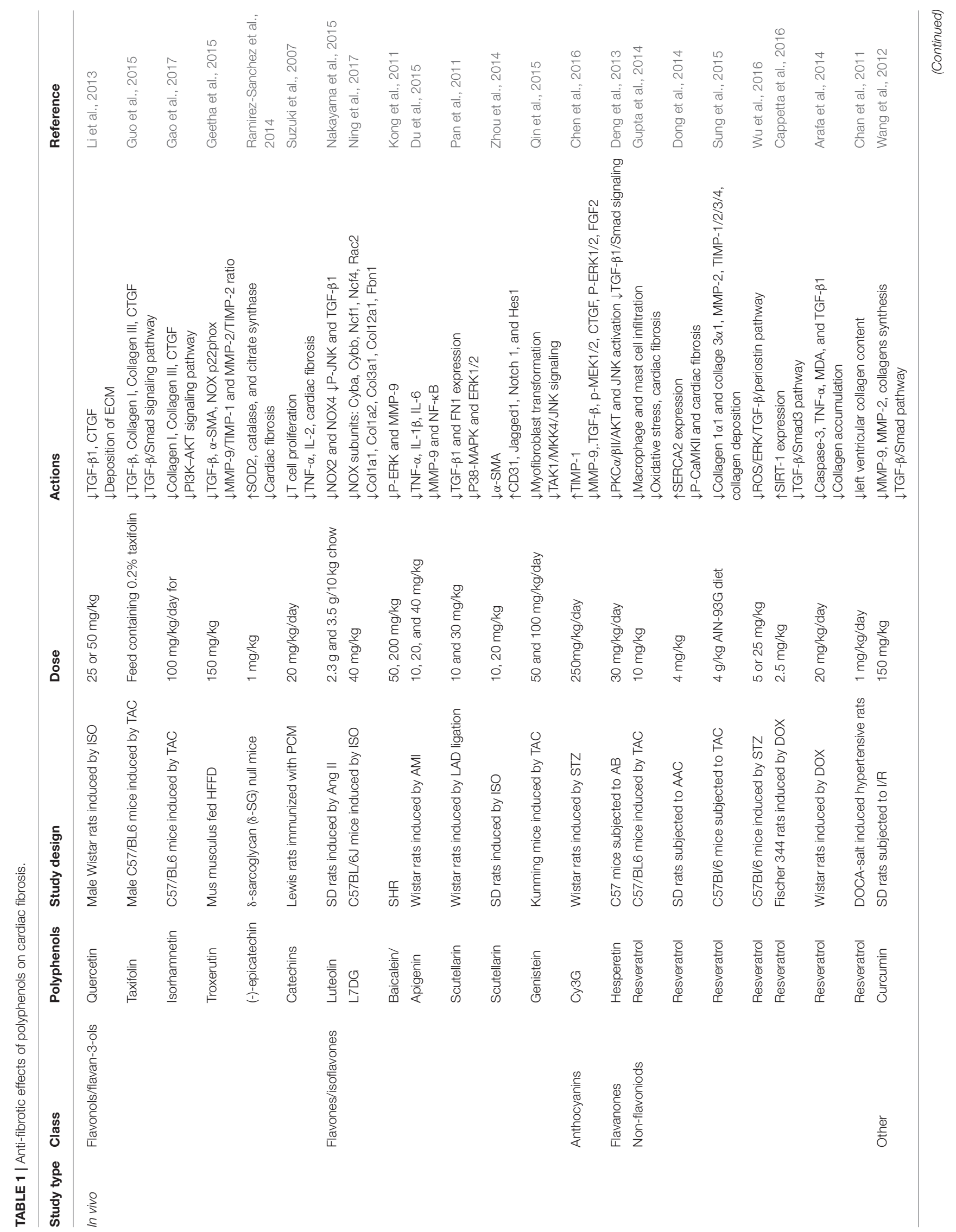




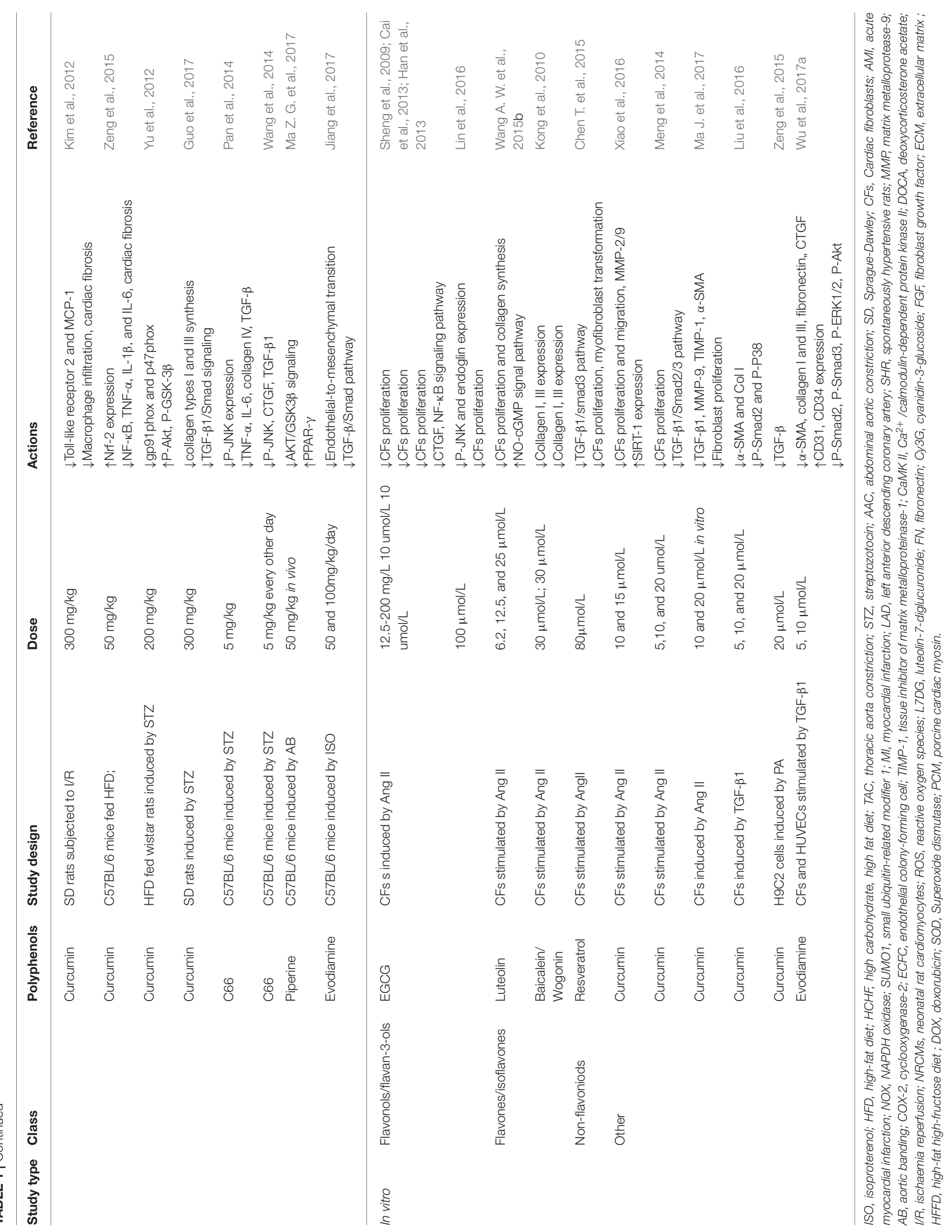


tea (Mak, 2012). EGCG inhibits CFs proliferation in rats and alleviates cardiac hypertrophy (Sheng et al., 2009). Guo et al. indicated that EGCG retarded cardiac hypertrophy in vivo and in vitro via the inhibition of oxidative stress (Sheng et al., 2007). Meanwhile, it attenuated the activation of rat CFs stimulated by AngII via the mediation of $\beta$-arrestin1 (Han et al., 2013). Liu et al. found that EGCG could decrease collagen synthesis and fibronectin expression in rat CFs induced by Ang II; moreover, it markedly ameliorated the excessive expression of CTGF and cardiac fibrosis via the blockage of the NF- $\kappa$ B signaling pathway in the hypertrophic stimulation (Cai et al., 2013). Additionally, EGCG inhibits the expression of endoglin stimulated by Ang II in CFs via the blockage of the JNK signaling pathway, thus slowing down the CFs proliferation in vitro and mitigating reparative scar fibrosis following MI (Lin et al., 2016). In the model of muscular dystrophies, epicatechin attenuates oxidative stress and improves mitochondrial function, thus decreasing heart fibrosis in $\delta$-sarcoglycan null mice (Ramirez-Sanchez et al., 2014). Catechin administration decreases tumor necrosis factor (TNF- $\alpha$ ) and Th2 cytokines secretion in the heart tissues and mitigates cardiac fibrosis in rat autoimmune myocarditis (Suzuki et al., 2007). However, the protective role of EGCG in attenuating cardiac fibrosis depends on a proper dose. Conversely, a high dose of EGCG results in cardiac collagen synthesis and aggravates cardiac fibrosis in mice (Cai et al., 2015).

\section{Flavones/Isoflavones in Cardiac Fibrosis}

Luteolin is one of the flavones that can be extracted from thyme, onion, broccoli, and cauliflower. It inhibits CFs proliferation via the reduction of oxidative stress in vitro (Wang T. et al., 2015), the mechanism where underlying anti-oxidative stress depends on the inhibition of NOX2 and NOX4 in cardiac hypertrophy, thus decreasing the phosphorylation of JNK and TGF- $\beta 1$ expression and alleviating cardiac fibrosis (Nakayama et al., 2015). Zhang et al. have indicated that luteolin-7-diglucuronide, another flavonoid glycoside, prevents ISO-induced myocardial fibrosis resulting from the downregulation of NOX and fibrogenesisassociated gene expression (Ning et al., 2017). Baicalein and wogonin are two of the main active ingredients in the Scutellaria baicalensis Georgi. In the CFs, baicalein and wogonin treatment suppresses collagen I and collagen III expression stimulated by Ang II (Kong et al., 2010). They also reduce myocardial collagen volume fraction and inhibit myocardial collagen I and III mRNA expression in spontaneously hypertensive rats by mediating ERK and MMP-9 pathways (Kong et al., 2010, 2011). Our lab indicated that baicalein treatment alleviated cardiac hypertrophy in vivo and in vitro. The mechanism underlying an anti-hypertrophic response resulted from the inhibition of MAPK kinase (MEK)-ERK1/2 signaling and GATA4 activation, and alleviation of interstitial fibrosis was observed in hypertrophic cardiac tissues following the administration of baicalein (Zong et al., 2013). In another cardiac hypertrophy model stimulated by Ang II infusion, baicalein also reduced Ang II-induced myocardial hypertrophy and collagen deposition (Wang A. W. et al., 2015). Consistent with previous studies about luteolin, baicalein not only attenuates cardiac fibrosis but also prevents the downregulation of SERCA2a and modulates intracellular $\mathrm{Ca}^{2+}$ concentration (Zhao et al., 2016). Apigenin, one of the flavones, modulates the activity of PPAR- $\gamma$ and the glucose/lipid metabolism (Maron, 2004). Recent studies indicate that apigenin also attenuates myocardial injury induced by ISO via regulating the activity of PPAR- $\gamma$ in diabetic rats (Buwa et al., 2016). Our group demonstrated that the administration of apigenin mitigated cardiac remodeling via inhibition of oxidative stress, the NF- $\kappa \mathrm{B}$ pathway and apoptosis, and reduced cardiac interstitial fibrosis in STZ-induced diabetic cardiomyopathy (Liu et al., 2017). Furthermore, due to antiinflammatory and anti-oxidative properties, apigenin treatment inhibits matrix metalloprotease- 9 and inflammatory reactions after acute myocardial injury (Du et al., 2015; Gutiérrez-Venegas and González-Rosas, 2017) and decreases cardiac fibrosis in the progression of MI (Gutiérrez-Venegas and GonzálezRosas, 2017). In a rat cardiac hypertrophy model induced by renovascular hypertension, administration of apigenin improved hypertensive cardiac dysfunction and abnormal myocardial glucolipid metabolism (Zhu et al., 2016). Similarly, scutellarin, as one of the members of the flavones, inhibits the proliferation and collagen production of CFs in vitro and suppresses the upregulation of fibronectin and TGF- $\beta 1$ induced by Ang II (Pan et al., 2011). Recent studies elucidate that the anti-fibrotic effect of scutellarin could be attributed to the inhibition of endothelialmesenchymal transition (EndoMT) following the stimulation of ISO in a rat (Zhou et al., 2014). Other flavones such as nobiletin (Parkar et al., 2016; Zhang et al., 2016), vitexin (Dong et al., 2011; Che et al., 2016), tangerentin (Vaiyapuri et al., 2013) not only possess an anti-oxidative and anti-inflammatory therapeutic effect but also exert a potent anti-fibrotic effect in an experimental animal model of cardiovascular diseases.

Isoflavones, such as genistein and daidzein, are present in large quantities in soybeans and exert beneficial anti-fibrotic effects on cardiac remodeling. Recent studies indicate that a genistein supplement attenuates ISO-induced cardiac hypertrophy in rats (Maulik et al., 2012) and inhibits TGF- $\beta 1$-induced proliferation, collagen production and myofibroblast transformation (Qin et al., 2015). Genistein treatment enhances endothelial colonyforming cell (ECFC) proliferation and migration, and transplants of genistein-stimulated ECFCs into myocardial ischemic sites in vivo stimulate cell proliferation and secretion of angiogenic cytokines at the ischemic sites, thereby alleviating myocardial fibrosis after cardiac function (Lee et al., 2014).

\section{Anthocyanins in Cardiac Fibrosis}

Anthocyanins such as malvidin-3-glucoside, delphinidin-3glucoside (Dp3G), cyanidin-3-glucoside (Cy3G), petunidin3-glucoside $(\mathrm{Pg} 3 \mathrm{G})$, and peonidin-3-glucoside from grape skins exert protective effects over the complication of ischemia/reperfusion (Liobikas et al., 2016) and diabetes mellitus (Sun et al., 2012). Dp3G and Cy3G, but not Pg3G, could recover ischemia-induced damage of complex I of the mitochondrial respiratory chain and increase ischemia-depleted ATP levels by promoting oxidative phosphorylation (Skemiene et al., 2015). Due to the high capacity to decrease cytosolic cytochrome c, Cy3G, but not Pg3G, prevents the rat heart from ischemia/reperfusion-induced apoptosis and necrosis (Škemiene 
et al., 2013). Administration of Cy3G attenuates cardiac dysfunction and cardiac inflammation in STZ-induced diabetic cardiomyopathy and decreases collagen disposition via activation of matrix metalloproteinase-9 (MMP-9) and reduction in the level of tissue inhibitor of matrix metalloproteinase (TIMP)-1 observed in diabetic rat heart (Chen et al., 2016). When taken together, experimental data suggest that anthocyanins with high reductive capacity can decrease cytosolic cytochrome c, inhibit caspase-associated apoptosis and necrosis in the ischemic/reperfused myocardium, and rescue deteriorating fibrosis in a diabetic rat heart. However, the anti-oxidative and anti-fibrotic effect on other cardiovascular diseases, such as MI and pressure overload, still need to be well-investigated.

\section{Flavanones in Cardiac Fibrosis}

The flavanone hesperitin, presented in citrus peels, has been shown to possess beneficial cardiovascular effects in different animal models (Roohbakhsh et al., 2015). The increased intake of flavanones tends to reduce the incidence of coronary heart diseases (Hertog et al., 1993; Geleijnse et al., 2002). Due to its anti-oxidative and anti-apoptosis properties, hesperitin reversed doxorubicin (Dox)-induced oxidative stress and decreased apoptosis in H9C2 cells stimulated by lipopolysaccharide through the mitochondria-dependent intrinsic apoptotic pathway (Yang et al., 2014). The inhibitory effect of hesperitin on cardiac remodeling by blocking the JNK and TGF $\beta 1 /$ Smad signaling pathways and mitigating fibrosis has been reported by our research group (Deng et al., 2013). Hesperidin, as a flavanone glycoside, plays a protective role in ISO-induced myocardial ischemia through the inhibition of lipid peroxidative and oxidative stress (Selvaraj and Pugalendi, 2010). Hesperidin could also increase the mRNA expression of Nrf-2 to exert a protective role in the heart of aged rats (Elavarasan et al., 2012). Moreover, a significant decrease in cardiac function biomarkers, including serum creatine kinase, aspartate aminotransferase, and lactate dehydrogenase, in diabetic rats has been detected following hesperidin supplement (Mahmoud et al., 2012).

Another citrus flavanone, naringenin, has been shown to possess protective effects on lipid metabolism. Mulvihill elegantly indicated that naringenin treatment ameliorated dyslipidemia, reduced increased VLDL levels and improved insulin sensitivity in $\mathrm{Ldlr}^{-/-}$mice fed a western diet through a PPAR- $\gamma$ coactivator $1 \alpha /$ PPAR- $\alpha$ mediated transcription program (Mulvihill et al., 2009). In a $\mathrm{H}_{2} \mathrm{O}_{2}$-treated cardiomyoblast, naringenin treatment attenuated stress-induced apoptotic cell death and lipid peroxidation and increased the level of reduced glutathione, whose protective effect mainly depends on the upregulation of Nrf-2 and downregulation of the NF- $\kappa$ B signaling pathway (Ramprasath et al., 2014). Due to its significantly antioxidative effect, recent studies indicate that naringenin plays a beneficial role in the models of age-associated cardiac disorders (Da Pozzo et al., 2017), hyperglycemia-induced cardiomyocyte injuries (Chtourou et al., 2015; You et al., 2016) and Doxinduced rat cardiotoxicity (Subburaman et al., 2014). Our results reveal that administration of naringenin ameliorates cardiac hypertrophy by inhibiting the activation of JNK, ERK, and
phosphatidylinositol-3-kinase/Akt signaling pathways, and it mitigates myocardial fibrosis (Zhang et al., 2015); however, the mechanism underlying the anti-fibrotic effect needs to be clarified.

\section{Some Non-flavonoids in Cardiac Fibrosis}

Resveratrol is a naturally occurring polyphenol mainly contained in plants. A supplement of resveratrol has been shown to prevent and/or slow down the progression of cardiac remodeling in multiple animal models of heart failure (Sung and Dyck, 2015). Recent studies have shown that treatment of resveratrol could activate sirtuins-3 (SIRT-3) and decrease collagen accumulation. Moreover, in vitro studies indicated that resveratrol treatment inhibited CFs proliferation and fibroblastto-myofibroblast transition stimulated by Ang II via blunting the TGF- $\beta /$ Smad3 pathway (Chen T. et al., 2015). Resveratrol can activate adenosine 5-monophosphate-activated protein kinase (AMPK) and extend the rat's lifespan, while it loses its protective effect in AMPK $\alpha 1 / \alpha 2$-knockout mice (Um et al., 2010). Treatment of resveratrol reversed cardiac remodeling and mitigated cardiac dysfunction by enhancing autophagy via the activation of AMPK (Kanamori et al., 2013). Ren et al. demonstrated that treatment with resveratrol mitigated aging-induced $\mathrm{O}_{2}^{-}$generation and mechanical dysfunction in cardiomyocytes stimulated by aldehyde dehydrogenase 2 activator Alda-1 (Zhang et al., 2014). Resveratrol supplement has been shown to suppress the interstitial and perivascular fibrosis induced by pressure overload in mice and rats (Dong et al., 2014; Gupta et al., 2014). Dyck et al. demonstrated that the mRNA expression of collagen I and III, MMP-2 TIMP$1 / 2 / 3 / 4$, and collagen deposition was suppressed by resveratrol, and its anti-fibrotic effect was partially attributed to AMPK activation (Sung et al., 2015). Meanwhile, resveratrol is known for its anti-oxidant and anti-inflammatory properties (BonnefontRousselot, 2016). Supplementation of resveratrol exhibited an anti-proliferative effect on CFs via blocking the ROS/ERK pathway and attenuated fibroblasts-myofibroblast transition via inhibiting the ROS/ERK/TGF- $\beta$ /periostin pathway in STZinduced diabetic cardiomyopathy (Wu et al., 2016). In doxinduced cardiotoxicity, it has been found that fibroblasts isolated from the resveratrol-treated group have decreased levels of TGF- $\beta /$ Smad3 expression and up-regulated sirt1 expression; consistent with the results in vivo, resveratrol supplement mitigates myocardial stiffness and collagen deposition (Cappetta et al., 2016). It was shown that Dox up-regulated not only TGF- $\beta 1$ expression but also stimulated massive collagen accumulation in left ventricle tissues, whereas the dox-induced fibrotic effect was attenuated by resveratrol (Arafa et al., 2014). In another study, the anti-fibrotic effect on cardiac remodeling was observed in deoxycorticosterone acetate-treated rats following resveratrol treatment (Chan et al., 2011). Although the studies about the anti-fibrotic effect of resveratrol are very scarce, preclinical studies have obtained promising and, in some cases, exciting results for the retardation and/or therapy of hypertension and ischemia-reperfusion injuries (Zordoky et al., 2015). Therefore, if these exciting animal results translate to humans, resveratrol may provide a novel 
and promising agent for the treatment of cardiovascular diseases.

\section{Curcumin}

Previous studies have shown that curcumin, a natural p300specific histone acetyltransferase (HAT) inhibitor, exerts a therapeutic effect on heart failure (Sunagawa et al., 2011). In the MI, curcumin only or combined with enalapril improves the left ventricular systolic function by inhibiting nuclear expression of p300 and mitigates extensive perivascular fibrosis in rats (Sunagawa et al., 2011, 2014). Another study has shown that curcumin mitigates maladaptive cardiac repair and reduces cardiac fibrotic response after ischemia and reperfusion by decreasing ECM degradation and inhibiting the synthesis of collagens via the TGF- $\beta /$ Smad pathway (Wang et al., 2012). Another study revealed that curcumin significantly ameliorated collagen accumulation in vivo and inhibited CFs proliferation and migration as well as MMP expression. Moreover, curcumin pretreatment downregulated the expression of SIRT-1 after MI, which demonstrated that the activation of SIRT1 was implicated in the beneficial role of curcumin (Xiao et al., 2016). In spontaneously hypertensive rats, treatment with curcumin decreases the expression of fibrotic markers CTGF, collagen III, and fibronectin. The inhibitory effect of collagen synthesis in the isolated fibroblasts stimulated by Ang II depends on inhibiting the TGF- $\beta 1 / \mathrm{Smad} 2 / 3$ pathway (Meng et al., 2014). Moreover, curcumin can also inhibit fibroblast differentiation in ISO and TGF- $\beta$ stimulated CFs (Liu et al., 2016; Ma et al., 2016) and ameliorate myocardial collagen deposition. Furthermore, curcumin treatment suppresses the increased expression of tolllike receptor 2 and MCP-1 in cardiomyocytes following TNF$\alpha$ stimulation or ischemia-reperfusion injury and decreases the fibrotic response observed in cardiac tissues (Kim et al., 2012). The protective role of curcumin is closely associated with its capacity to up-regulate Nrf-2 expression and repress NF- $\mathrm{KB}$ activation (Zeng et al., 2015). Curcumin could regulate the Akt/GSK-3 $\beta$ signaling pathway and NOX expression in diabetic cardiomyopathy and ameliorate cardiac fibrosis(Yu et al., 2012); t the anti-fibrotic mechanism is associated with the inhibition of collagen type I and III synthesis and TGF$\beta 1 /$ Smad signaling (Guo et al., 2017). Additionally, the same cardioprotective effect is achieved by a new mono-carbonyl curcumin analog, Y20 (Qian et al., 2015). A novel curcumin derivative, C66, has ability to mitigate high glucose-induced inflammatory and apoptosis and inhibit JNK phosphorylation in both $\mathrm{H} 9 \mathrm{C} 2$ cells and neonatal cardiomyocytes, and C66 treatment also improves cardiac function and extensive fibrosis in diabetic mice In addition, the same cardioprotective effect was achieved by new mono-carbonyl curcumin analog, Y20(Pan et al., 2014). Moreover, cardiac metallothionein expression and fibrosis is markedly suppressed by administration of C66 via inhibiting the diabetic upregulation of JNK phosphorylation in mice (Wang et al., 2014).

\section{Piperine/Evodiamine}

A previous study found that piperine could attenuate weight gain in rodents (BrahmaNaidu et al., 2014), and the beneficial effect of piperine was associated with the up-regulation of the metabolic rate of resting muscle (Nogara et al., 2016). In the metabolic syndrome model, piperine reduced ventricular wall thickness and attenuated cardiac collagen deposition in rats fed a high-fat diet (Diwan et al., 2013). Furthermore, pretreatment of piperine ameliorates oxidative stress, dyslipidemia, and fibrosis in ISO-induced myocardial ischemia (Dhivya et al., 2017). Our lab has reported that piperine administration mitigates cardiac fibrosis induced by pressure-overload or ISO simulation in mice. Isolated CFs transition induced by TGF- $\beta$ could be attenuated by piperine via inhibition of the AKT/GSK3 $\beta$ pathway (Ma Z. G. et al., 2017). Endothelial-to-mesenchymal transition participates in cardiac fibrosis in the progression of cardiac remodeling. Evodiamine is the major ingredient isolated from the fruit of E. rutaecarpa. Our study indicated that evodiamine ameliorated cardiac dysfunction and retarded cardiac fibrosis induced by ISO stimulation via mediating EndoMT in vivo (Jiang et al., 2017); the anti-fibrotic effect and mechanism in fibroblast stimulated by TGF- $\beta$ was observed following evodiamine administration ( Wu et al., 2017a).

\section{CHALLENGES AND FUTURE DIRECTION}

Cardiac fibrosis is a prevalent pathology in response to stress and injury. It is abundantly clear that the extensive understanding of fibrosis-associated mechanisms is critical to obtain exciting advancements in the treatment of cardiac fibrosis. Given the complicated development of cardiac fibrosis, conventional therapies, such as $\beta$-blockers and RAAS inhibitors, do not completely hamper the progression of cardiac fibrosis in patients with heart failure. Therefore, an additional or novel treatment with some polyphenols might provide a potential strategy to alleviate cardiac fibrosis, as it has been shown to target CFs differentiation and pro-fibrotic molecular signals (Figure 2).

Many epidemiological studies have indicated that the consumption of natural polyphenols is associated with a reduced risk of suffering from chronic diseases. The increased intake of fruits and vegetables is inversely associated with major cardiovascular diseases, MI, and cardiovascular mortality (Miller et al., 2017). A dietary supplement of polyphenols provides a convenient way to prevent the occurrence of cardiovascular disease and fibrosis. Moreover, some polyphenols possess antioxidant and anti-inflammatory properties, and comprehensive animal experimental studies found that some polyphenols could be regarded as a potential agent to treat cardiac fibrosis. Multiple lines of evidence exploring the cardioprotective effects of resveratrol have obtained promising results; however, there is still a long way to determine whether resveratrol will finally translate from the laboratory to the clinic (Rauf et al., 2017). Despite some progress made in polyphenols research in animal models of cardiac fibrosis, there are major gaps that need to be settled. First, long-term trials (animal and human) must be performed to evaluate the therapeutic effect and toxicity of polyphenols. Second, the efficiency and bioavailability of polyphenols in its absorption and metabolism need to be considered. As the dose of polyphenols will have to be examined, 


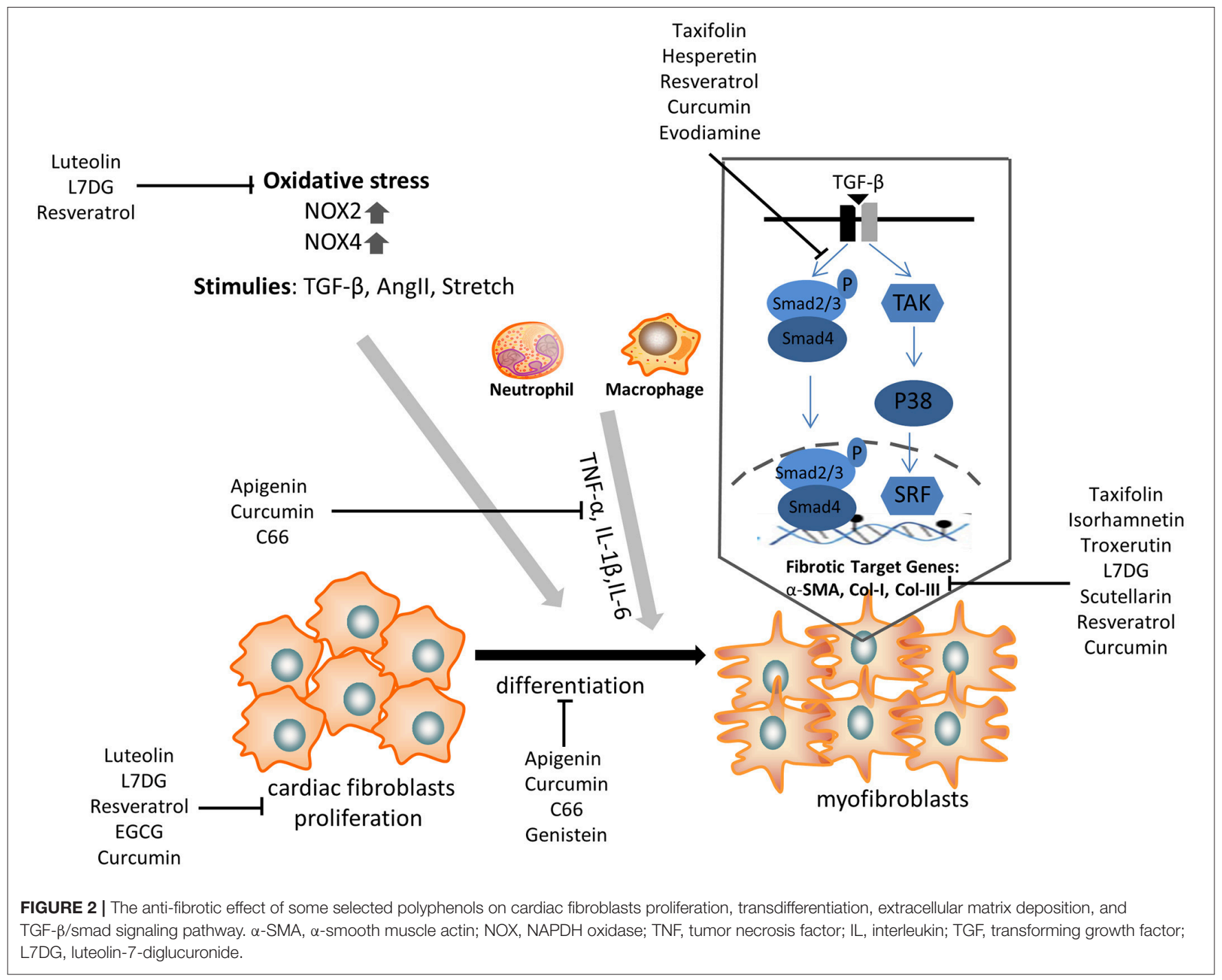

consideration must be whether made as to administration with individual flavonoids, flavonoid combinations, or simply dietary recommendations on polyphenols supplement represents the effective approach for the rapid translation of these lab results into effective interventions for cardiac fibrosis. Thus, understanding the anti-fibrotic targets of polyphenols and their structure-activity relationship, improved screening methods, and achieved positive results of clinical trials will be critical to specify the future direction for new drug discovery. Collectively, our review suggests that some polyphenols in experimental studies could target fibrotic mechanisms and thus may be a potential therapeutic agent for cardiac fibrosis.

\section{REFERENCES}

Al Hattab, D., and Czubryt, M. P. (2017). A Primer on current progress in cardiac fibrosis. Can. J. Physiol. Pharmacol. 95, 1091-1099. doi: 10.1139/cjpp-2016-0687

Arafa, M. H., Mohammad, N. S., Atteia, H. H., and Abd-Elaziz, H. R. (2014).

Protective effect of resveratrol against doxorubicin-induced cardiac toxicity

\section{AUTHOR CONTRIBUTIONS}

$\mathrm{NZ}$ and $\mathrm{W}-\mathrm{YW}$ were responsible for assembling and drafting of the manuscript. L-LL, CH, and Q-ZT contributed to the drafting of the manuscript.

\section{ACKNOWLEDGMENTS}

This study was supported by grants obtained from the Key Project of the National Natural Science Foundation (No. 81530012), the National Natural Science Foundation of China (No. 81470516, No. 81270303).

and fibrosis in male experimental rats. J. Physiol. Biochem. 70, 701-711. doi: 10.1007/s13105-014-0339-y

Bando, M. (2016). Pirfenidone: clinical trials and clinical practice in patients with idiopathic pulmonary fibrosis. Respir. Investig. 54, 298-304. doi: 10.1016/j.resinv.2016.03.007

Banerjee, I., Fuseler, J. W., Intwala, A. R., and Baudino, T. A. (2009). IL6 loss causes ventricular dysfunction, fibrosis, reduced capillarydensity, 
and dramatically alters the cell populations of the developing and adult heart. Am. J. Physiol. Heart Circ. Physiol. 296, H1694-H1704. doi: 10.1152/ajpheart.00908.2008

Bauersachs, J., Galuppo, P., Fraccarollo, D., Christ, M., and Ertl, G. (2001). Improvement of left ventricular remodeling and function by hydroxymethylglutaryl coenzyme a reductase inhibition with cerivastatin in rats with heart failure after myocardial infarction. Circulation 104, 982-985. doi: 10.1161/hc3401.095946

Bonnefont-Rousselot, D. (2016). Resveratrol and cardiovascular diseases. Nutrients 8:250. doi: 10.3390/nu8050250

BrahmaNaidu, P., Nemani, H., Meriga, B., Mehar, S. K., Potana, S., and Ramgopalrao, S. (2014). Mitigating efficacy of piperine in the physiological derangements of high fat diet induced obesity in Sprague Dawley rats. Chem. Biol. Interact. 221, 42-51. doi: 10.1016/j.cbi.2014.07.008

Buwa, C. C., Mahajan, U. B., Patil, C. R., and Goyal, S. N. (2016). Apigenin attenuates beta-receptor-stimulated myocardial injury via safeguarding cardiac functions and escalation of antioxidant defence system. Cardiovasc. Toxicol. 16, 286-297. doi: 10.1007/s12012-015-9336-9

Cai, Y., He, S. Q., Hong, H. Q., Cai, Y. P., Zhao, L., and Zhang, M. (2015). High doses of (-)-epigallocatechin-3-gallate from green tea induces cardiac fibrosis in mice. Biotechnol. Lett. 37, 2371-2377. doi: 10.1007/s10529-015-1926-x

Cai, Y., Yu, S. S., Chen, T. T., Gao, S., Geng, B., Yu, Y., et al. (2013). EGCG inhibits CTGF expression via blocking NF-KB activation in cardiac fibroblast. Phytomedicine 20, 106-113. doi: 10.1016/j.phymed.2012.10.002

Cappetta, D., Esposito, G., Piegari, E., Russo, R., Ciuffreda, L. P., Rivellino, A., et al. (2016). SIRT1 activation attenuates diastolic dysfunction by reducing cardiac fibrosis in a model of anthracycline cardiomyopathy. Int. J. Cardiol. 205, 99-110. doi: 10.1016/j.ijcard.2015.12.008

Chan, V., Fenning, A., Iyer, A., Hoey, A., and Brown, L. (2011). Resveratrol improves cardiovascular function in DOCA-salt hypertensive rats. Curr. Pharm. Biotechnol. 12, 429-436. doi: 10.2174/138920111794480552

Che, X., Wang, X., Zhang, J., Peng, C., Zhen, Y., Shao, X., et al. (2016). Vitexin exerts cardioprotective effect on chronic myocardial ischemia/reperfusion injury in rats via inhibiting myocardial apoptosis and lipid peroxidation. Am. J. Transl. Res. 8, 3319-3328.

Chen, T., Li, J., Liu, J., Li, N., Wang, S., Liu, H., et al. (2015). Activation of SIRT3 by resveratrol ameliorates cardiac fibrosis and improves cardiac function via the TGF-beta/Smad3 pathway. Am. J. Physiol. Heart Circ. Physiol. 308, H424H434. doi: 10.1152/ajpheart.00454.2014

Chen, X. Q., Liu, X., Wang, Q. X., Zhang, M. J., Guo, M., Liu, F., et al. (2015). Pioglitazone inhibits angiotensin II-induced atrial fibroblasts proliferation via NF-kB/TGF-beta1/TRIF/TRAF6 pathway. Exp. Cell Res. 330, 43-55. doi: 10.1016/j.yexcr.2014.08.021

Chen, Y. F., Shibu, M. A., Fan, M. J., Chen, M. C., Viswanadha, V. P., Lin, Y. L., et al. (2016). Purple rice anthocyanin extract protects cardiac function in STZ-induced diabetes rat hearts by inhibiting cardiac hypertrophy and fibrosis. J. Nutr. Biochem. 31, 98-105. doi: 10.1016/j.jnutbio.2015. 12.020

Christia, P., Bujak, M., Gonzalez-Quesada, C., Chen, W., Dobaczewski, M., Reddy, A., et al. (2013). Systematic characterization of myocardial inflammation, repair, and remodeling in a mouse model of reperfused myocardial infarction. J. Histochem. Cytochem. 61, 555-570. doi: 10.1369/00221554134 93912

Chtourou, Y., Slima, A. B., Makni, M., Gdoura, R., and Fetoui, H. (2015). Naringenin protects cardiac hypercholesterolemia-induced oxidative stress and subsequent necroptosis in rats. Pharmacol. Rep. 67, 1090-1097. doi: 10.1016/j.pharep.2015.04.002

Chuva de Sousa Lopes, S. M., Feijen, A., Korving, J., Korchynskyi, O., Larsson, J., Karlsson, S., et al. (2004). Connective tissue growth factor expression and Smad signaling during mouse heart development and myocardial infarction. Dev. Dyn. 231, 542-550. doi: 10.1002/dvdy. 20162

Cucoranu, I., Clempus, R., Dikalova, A., Phelan, P. J., Ariyan, S., Dikalov, S., et al. (2005). $\mathrm{NAD}(\mathrm{P}) \mathrm{H}$ oxidase 4 mediates transforming growth factor-betal-induced differentiation of cardiac fibroblasts into myofibroblasts. Circ. Res. 97, 900-907. doi: 10.1161/01.RES.0000187457.2 $4338.3 \mathrm{D}$
Czuwara-Ladykowska, J., Gore, E. A., Shegogue, D. A., Smith, E. A., and Trojanowska, M. (2001). Differential regulation of transforming growth factor-beta receptors type I and II by platelet-derived growth factor in human dermal fibroblasts. Br. J. Dermatol. 145, 569-575. doi: $10.1046 / j .1365-2133.2001 .04443 . x$

Da Pozzo, E., Costa, B., Cavallini, C., Testai, L., Martelli, A., Calderone, V., et al. (2017). The citrus flavanone naringenin protects myocardial cells against age-associated damage. Oxid. Med. Cell. Longev. 2017:9536148. doi: $10.1155 / 2017 / 9536148$

Davis, J., and Molkentin, J. D. (2014). Myofibroblasts: trust your heart and let fate decide. J. Mol. Cell. Cardiol. 70, 9-18. doi: 10.1016/j.yjmcc.2013. 10.019

Del Rio, D., Rodriguez-Mateos, A., Spencer, J. P., Tognolini, M., Borges, G., and Crozier, A. (2013). Dietary (poly)phenolics in human health: structures, bioavailability, and evidence of protective effects against chronic diseases. Antioxid. Redox Signal. 18, 1818-1892. doi: 10.1089/ars.2012. 4581

Deng, W., Jiang, D., Fang, Y., Zhou, H., Cheng, Z., Lin, Y., et al. (2013). Hesperetin protects against cardiac remodelling induced by pressure overload in mice. J. Mol. Histol. 44, 575-585. doi: 10.1007/s10735-0139514-7

Dhivya, V., Priya, L. B., Chirayil, H. T., Sathiskumar, S., Huang, C. Y., and Padma, V. V. (2017). Piperine modulates isoproterenol induced myocardial ischemia through antioxidant and anti-dyslipidemic effect in male Wistar rats. Biomed. Pharmacother. 87, 705-713. doi: 10.1016/j.biopha.2017. 01.002

Diwan, V., Poudyal, H., and Brown, L. (2013). Piperine attenuates cardiovascular, liver and metabolic changes in high carbohydrate, high fat-fed rats. Cell Biochem. Biophys. 67, 297-304. doi: 10.1007/s12013-011-9306-1

Dobaczewski, M., Bujak, M., Li, N., Gonzalez-Quesada, C., Mendoza, L. H., Wang, X. F., et al. (2010). Smad3 signaling critically regulates fibroblast phenotype and function in healing myocardial infarction. Circ. Res. 107, 418-428. doi: 10.1161/CIRCRESAHA.109.216101

Dobaczewski, M., Chen, W., and Frangogiannis, N. G. (2011). Transforming growth factor (TGF)-beta signaling in cardiac remodeling. J. Mol. Cell. Cardiol. 51, 600-606. doi: 10.1016/j.yjmcc.2010.10.033

Dong, L., Fan, Y., Shao, X., and Chen, Z. (2011). Vitexin protects against myocardial ischemia/reperfusion injury in Langendorff-perfused rat hearts by attenuating inflammatory response and apoptosis. Food Chem. Toxicol. 49, 3211-3216. doi: 10.1016/j.fct.2011.09.040

Dong, Q., Wu, Z., Li, X., Yan, J., Zhao, L., Yang, C., et al. (2014). Resveratrol ameliorates cardiac dysfunction induced by pressure overload in rats via structural protection and modulation of $\mathrm{Ca}^{2+}$ cycling proteins. J. Transl. Med. 12:323. doi: 10.1186/s12967-014-0323-x

Du, H., Hao, J., Liu, F., Lu, J., and Yang, X. (2015). Apigenin attenuates acute myocardial infarction of rats via the inhibitions of matrix metalloprotease- 9 and inflammatory reactions. Int. J. Clin. Exp. Med. 8, 8854-8859.

Elavarasan, J., Velusamy, P., Ganesan, T., Ramakrishnan, S. K., Rajasekaran, D., and Periandavan, K. (2012). Hesperidin-mediated expression of Nrf2 and upregulation of antioxidant status in senescent rat heart. J. Pharm. Pharmacol. 64, 1472-1482. doi: 10.1111/j.2042-7158.2012.01512.x

Engebretsen, K. V., Skårdal, K., Bjørnstad, S., Marstein, H. S., Skrbic, B., Sjaastad, I., et al. (2014). Attenuated development of cardiac fibrosis in left ventricular pressure overload by SM16, an orally active inhibitor of ALK5. J. Mol. Cell. Cardiol. 76, 148-157. doi: 10.1016/j.yjmcc.2014.08.008

Frangogiannis, N. G. (2017). The extracellular matrix in myocardial injury, repair, and remodeling. J. Clin. Invest. 127, 1600-1612. doi: 10.1172/JCI87491

Frieler, R. A., and Mortensen, R. M. (2015). Immune cell and other noncardiomyocyte regulation of cardiac hypertrophy and remodeling. Circulation 131, 1019-1030. doi: 10.1161/CIRCULATIONAHA.114.008788

Gao, L., Yao, R., Liu, Y., Wang, Z., Huang, Z., Du, B., et al. (2017). Isorhamnetin protects against cardiac hypertrophy through blocking PI3K-AKT pathway. Mol. Cell. Biochem. 429, 167-177. doi: 10.1007/s11010-017-2944-x

Geetha, R., Radika, M. K., Priyadarshini, E., Bhavani, K., and Anuradha, C. V. (2015). Troxerutin reverses fibrotic changes in the myocardium of high-fat high-fructose diet-fed mice. Mol. Cell. Biochem. 407, 263-279. doi: 10.1007/s11010-015-2474-3 
Geetha, R., Yogalakshmi, B., Sreeja, S., Bhavani, K., and Anuradha, C. V. (2014). Troxerutin suppresses lipid abnormalities in the heart of high-fat-high-fructose diet-fed mice. Mol. Cell. Biochem. 387, 123-134. doi: 10.1007/s11010-013-1877-2

Geleijnse, J. M., Launer, L. J., Van der Kuip, D. A., Hofman, A., and Witteman, J. C. (2002). Inverse association of tea and flavonoid intakes with incident myocardial infarction: the Rotterdam Study. Am. J. Clin. Nutr. 75, 880-886. doi: 10.1093/ajcn/75.5.880

Guo, H., Zhang, X., Cui, Y., Zhou, H., Xu, D., Shan, T., et al. (2015). Taxifolin protects against cardiac hypertrophy and fibrosis during biomechanical stress of pressure overload. Toxicol. Appl. Pharmacol. 287, 168-177. doi: 10.1016/j.taap.2015.06.002

Guo, S., Meng, X. W., Yang, X. S., Liu, X. F., Ou-Yang, C. H., and Liu, C. (2017). Curcumin administration suppresses collagen synthesis in the hearts of rats with experimental diabetes. Acta Pharmacol. Sin. 39, 195-204. doi: 10.1038/aps.2017.92

Gupta, P. K., DiPette, D. J., and Supowit, S. C. (2014). Protective effect of resveratrol against pressure overload-induced heart failure. Food Sci. Nutr. 2, 218-229. doi: 10.1002/fsn3.92

Gutiérrez-Venegas, G., and González-Rosas, Z. (2017). Apigenin reduce lipoteichoic acid-induced inflammatory response in rat cardiomyoblast cells. Arch. Pharm. Res. 40, 240-249. doi: 10.1007/s12272-016-0756-2

Han, Y. S., Lan, L., Chu, J., Kang, W. Q., and Ge, Z. M. (2013). Epigallocatechin gallate attenuated the activation of rat cardiac fibroblasts induced by angiotensin II via regulating beta-arrestin1. Cell. Physiol. Biochem. 31, 338-346. doi: $10.1159 / 000343371$

Hertog, M. G., Feskens, E. J., Hollman, P. C., Katan, M. B., and Kromhout, D. (1993). Dietary antioxidant flavonoids and risk of coronary heart disease: the Zutphen elderly study. Lancet 342, 1007-1011. doi: 10.1016/0140-6736(93)92876-U

Heymans, S., Gonzalez, A., Pizard, A., Papageorgiou, A. P., Lopez-Andres, N., Jaisser, F., et al. (2015). Searching for new mechanisms of myocardial fibrosis with diagnostic and/or therapeutic potential. Eur. J. Heart Fail. 17, 764-771. doi: 10.1002/ejhf.312

Jiang, F., Chang, C. W., and Dusting, G. J. (2010). Cytoprotection by natural and synthetic polyphenols in the heart: novel mechanisms and perspectives. Curr. Pharm. Des. 16, 4103-4112. doi: 10.2174/138161210794519174

Jiang, X. H., Wu, Q. Q., Xiao, Y., Yuan, Y., Yang, Z., Bian, Z. Y., et al. (2017). Evodiamine prevents isoproterenol-induced cardiac fibrosis by regulating endothelial-to-mesenchymal transition. Planta Med. 83, 761-769. doi: 10.1055/s-0042-124044

Johar, S., Cave, A. C., Narayanapanicker, A., Grieve, D. J., and Shah, A. M. (2006). Aldosterone mediates angiotensin II-induced interstitial cardiac fibrosis via a Nox2-containing NADPH oxidase. FASEB J. 20, 1546-1548. doi: 10.1096/fj.05-4642fje

Kanamori, H., Takemura, G., Goto, K., Tsujimoto, A., Ogino, A., Takeyama, T., et al. (2013). Resveratrol reverses remodeling in hearts with large, old myocardial infarctions through enhanced autophagy-activating AMP kinase pathway. Am. J. Pathol. 182, 701-713. doi: 10.1016/j.ajpath.2012. 11.009

Kim, Y. S., Kwon, J. S., Cho, Y. K., Jeong, M. H., Cho, J. G., Park, J. C., et al. (2012). Curcumin reduces the cardiac ischemia-reperfusion injury: involvement of the toll-like receptor 2 in cardiomyocytes. J. Nutr. Biochem. 23, 1514-1523. doi: 10.1016/j.jnutbio.2011.10.004

Klapholz, M. (2009). Beta-blocker use for the stages of heart failure. Mayo Clin. Proc. 84, 718-729. doi: 10.4065/84.8.718

Kong, E. K., Huang, Y., Sanderson, J. E., Chan, K. B., Yu, S., and Yu, C. M. (2010). Baicalein and Wogonin inhibit collagen deposition in SHR and WKY cardiac fibroblast cultures. BMB Rep. 43, 297-303. doi: 10.5483/BMBRep.2010.43. 4.297

Kong, E. K., Yu, S., Sanderson, J. E., Chen, K. B., Huang, Y., and Yu, C. M. (2011). A novel anti-fibrotic agent, baicalein, for the treatment of myocardial fibrosis in spontaneously hypertensive rats. Eur. J. Pharmacol. 658, 175-181. doi: 10.1016/j.ejphar.2011.02.033

Kong, P., Christia, P., and Frangogiannis, N. G. (2014). The pathogenesis of cardiac fibrosis. Cell. Mol. Life Sci. 71, 549-574. doi: 10.1007/s00018-013-1349-6

Koshman, Y. E., Patel, N., Chu, M., Iyengar, R., Kim, T., Ersahin, C., et al. (2013). Regulation of connective tissue growth factor gene expression and fibrosis in human heart failure. J. Card. Fail. 19, 283-294. doi: 10.1016/j.cardfail.2013.01.013

Kuwahara, F., Kai, H., Tokuda, K., Kai, M., Takeshita, A., Egashira, K., et al. (2002). Transforming growth factor-beta function blocking prevents myocardial fibrosis and diastolic dysfunction in pressure-overloaded rats. Circulation 106, 130-135. doi: 10.1161/01.CIR.0000020689.12472.E0

Lee, S. H., Lee, J. H., Asahara, T., Kim, Y. S., Jeong, H. C., Ahn, Y., et al. (2014). Genistein promotes endothelial colony-forming cell (ECFC) bioactivities and cardiac regeneration in myocardial infarction. PLoS ONE 9:e96155. doi: 10.1371/journal.pone.0096155

Li, M., Jiang, Y., Jing, W., Sun, B., Miao, C., and Ren, L. (2013). Quercetin provides greater cardioprotective effect than its glycoside derivative rutin on isoproterenol-induced cardiac fibrosis in the rat. Can. J. Physiol. Pharmacol. 91 , 951-959. doi: 10.1139/cjpp-2012-0432

Lijnen, P. J., van Pelt, J. F., and Fagard, R. H. (2012). Stimulation of reactive oxygen species and collagen synthesis by angiotensin II in cardiac fibroblasts. Cardiovasc. Ther. 30, e1-e8. doi: 10.1111/j.1755-5922.2010.00205.x

Lin, C. M., Chang, H., Wang, B. W., and Shyu, K. G. (2016). Suppressive effect of epigallocatechin-3-O-gallate on endoglin molecular regulation in myocardial fibrosis in vitro and in vivo. J. Cell. Mol. Med. 20, 2045-2055. doi: $10.1111 /$ jcmm. 12895

Liobikas, J., Skemiene, K., Trumbeckaite, S., and Borutaite, V. (2016). Anthocyanins in cardioprotection: a path through mitochondria. Pharmacol. Res. 113, 808-815. doi: 10.1016/j.phrs.2016.03.036

Liu, H. J., Fan, Y. L., Liao, H. H., Liu, Y., Chen, S., Ma, Z. G., et al. (2017). Apigenin alleviates STZ-induced diabetic cardiomyopathy. Mol. Cell. Biochem. 428, 9-21. doi: 10.1007/s11010-016-2913-9

Liu, H., Liu, A., Shi, C., and Li, B. (2016). Curcumin suppresses transforming growth factor-betal-induced cardiac fibroblast differentiation via inhibition of Smad-2 and p38 MAPK signaling pathways. Exp. Ther. Med. 11, 998-1004. doi: 10.3892/etm.2016.2969

Ma, F., Li, Y., Jia, L., Han, Y., Cheng, J., Li, H., et al. (2012). Macrophagestimulated cardiac fibroblast production of IL-6 is essential for TGF beta/Smad activation and cardiac fibrosis induced by angiotensin II. PLOS ONE 7:e35144. doi: 10.1371/journal.pone.0035144

Ma, J., Ma, S. Y., and Ding, C. H. (2016). Curcumin reduces cardiac fibrosis by inhibiting myofibroblast differentiation and decreasing transforming growth factor betal and matrix metalloproteinase 9/tissue inhibitor of metalloproteinase 1. Chin. J. Integr. Med. 23, 362-369.

Ma, J., Ma, S. Y., and Ding, C. H. (2017). Curcumin reduces cardiac fibrosis by inhibiting myofibroblast differentiation and decreasing transforming growth factor betal and matrix metalloproteinase 9/tissue inhibitor of metalloproteinase 1. Chin. J. Integr. Med. 23, 362-369. doi: 10.1007/s11655-015-2159-5

Ma, Z. G., Yuan, Y. P., Zhang, X., Xu, S. C., Wang, S. S., and Tang, Q. Z. (2017). Piperine attenuates pathological cardiac fibrosis via PPARgamma/AKT pathways. EBioMedicine 18, 179-187. doi: 10.1016/j.ebiom.2017. 03.021

Mahmoud, A. M., Ashour, M. B., Abdel-Moneim, A., and Ahmed, O. M. (2012). Hesperidin and naringin attenuate hyperglycemia-mediated oxidative stress and proinflammatory cytokine production in high fat fed/streptozotocin-induced type 2 diabetic rats. J. Diabetes Complicat. 26, 483-490. doi: 10.1016/j.jdiacomp.2012.06.001

Mak, J. C. (2012). Potential role of green tea catechins in various disease therapies: progress and promise. Clin. Exp. Pharmacol. Physiol. 39, 265-273. doi: $10.1111 / \mathrm{j} .1440-1681.2012 .05673 . \mathrm{x}$

Maron, D. J. (2004). Flavonoids for reduction of atherosclerotic risk. Curr. Atheroscler. Rep. 6, 73-78. doi: 10.1007/s11883-004-0119-1

Maulik, S. K., Prabhakar, P., Dinda, A. K., and Seth, S. (2012). Genistein prevents isoproterenol-induced cardiac hypertrophy in rats. Can. J. Physiol. Pharmacol. 90, 1117-1125. doi: 10.1139/y2012-068

Maytin, M., Siwik, D. A., Ito, M., Xiao, L., Sawyer, D. B., Liao, R., et al. (2004). Pressure overload-induced myocardial hypertrophy in mice does not require gp91phox. Circulation 109, 1168-1171. doi: 10.1161/01.CIR.0000117229.60628.2F

Meng, Z., Yu, X. H., Chen, J., Li, L., and Li, S. (2014). Curcumin attenuates cardiac fibrosis in spontaneously hypertensive rats through PPAR-gamma activation. Acta Pharmacol. Sin. 35, 1247-1256. doi: 10.1038/aps.2014.63 
Miguel-Carrasco, J. L., Baltanás, A., Cebrián, C., Moreno, M. U., López, B., Hermida, N., et al. (2012). Blockade of TGF-beta 1 signalling inhibits cardiac NADPH oxidase overactivity in hypertensive rats. Oxid. Med. Cell. Longev. 2012:726940. doi: 10.1155/2012/726940

Miller, V., Mente, A., Dehghan, M., Rangarajan, S., Zhang, X., Swaminathan, S., et al. (2017). Fruit, vegetable, and legume intake, and cardiovascular disease and deaths in 18 countries (PURE): a prospective cohort study. Lancet 390, 2037-2049. doi: 10.1016/S0140-6736(17)32253-5

Mirkovic, S., Seymour, A. M., Fenning, A., Strachan, A., Margolin, S. B., Taylor, S. M., et al. (2002). Attenuation of cardiac fibrosis by pirfenidone and amiloride in DOCA-salt hypertensive rats. Br. J. Pharmacol. 135, 961-968. doi: 10.1038/sj.bjp.0704539

Mitchell, M. D., Laird, R. E., Brown, R. D., and Long, C. S. (2007). IL-1beta stimulates rat cardiac fibroblast migration via MAP kinase pathways. Am. J. Physiol. Heart Circ. Physiol. 292, H1139-H1147. doi: 10.1152/ajpheart.00881.2005

Mulvihill, E. E., Allister, E. M., Sutherland, B. G., Telford, D. E., Sawyez, C. G., Edwards, J. Y., et al. (2009). Naringenin prevents dyslipidemia, apolipoprotein $B$ overproduction, and hyperinsulinemia in LDL receptor-null mice with dietinduced insulin resistance. Diabetes 58, 2198-2210. doi: 10.2337/db09-0634

Murdoch, C. E., Chaubey, S., Zeng, L., Yu, B., Ivetic, A., Walker, S. J., et al. (2014). Endothelial NADPH oxidase-2 promotes interstitial cardiac fibrosis and diastolic dysfunction through proinflammatory effects and endothelial-mesenchymal transition. J. Am. Coll. Cardiol. 63, 2734-2741. doi: 10.1016/j.jacc.2014.02.572

Nakayama, A., Morita, H., Nakao, T., Yamaguchi, T., Sumida, T., Ikeda, Y., et al. (2015). A food-derived flavonoid luteolin protects against angiotensin II-induced cardiac remodeling. PLoS ONE 10:e0137106. doi: 10.1371/journal.pone.0137106

Nguyen, D. T., Ding, C., Wilson, E., Marcus, G. M., and Olgin, J. E. (2010). Pirfenidone mitigates left ventricular fibrosis and dysfunction after myocardial infarction and reduces arrhythmias. Heart Rhythm 7, 1438-1445. doi: 10.1016/j.hrthm.2010.04.030

Ning, B. B., Zhang, Y., Wu, D. D., Cui, J. G., Liu, L., Wang, P. W., et al. (2017). Luteolin-7-diglucuronide attenuates isoproterenol-induced myocardial injury and fibrosis in mice. Acta Pharmacol. Sin. 38, 331-341. doi: 10.1038/aps.2016.142

Niu, L., He, X. H., Wang, Q. W., Fu, M. Y., Xu, F., Xue, Y., et al. (2015). Polyphenols in regulation of redox signaling and inflammation during cardiovascular diseases. Cell Biochem. Biophys. 72, 485-494. doi: 10.1007/s12013-014-0492-5

Nogara, L., Naber, N., Pate, E., Canton, M., Reggiani, C., and Cooke, R. (2016). Piperine's mitigation of obesity and diabetes can be explained by its upregulation of the metabolic rate of resting muscle. Proc. Natl. Acad. Sci. U.S.A. 113, 13009-13014. doi: 10.1073/pnas.1607536113

Pan, Y., Wang, Y., Zhao, Y., Peng, K., Li, W., Wang, Y., et al. (2014). Inhibition of JNK phosphorylation by a novel curcumin analog prevents high glucoseinduced inflammation and apoptosis in cardiomyocytes and the development of diabetic cardiomyopathy. Diabetes 63, 3497-3511. doi: 10.2337/db13-1577

Pan, Z., Zhao, W., Zhang, X., Wang, B., Wang, J., Sun, X., et al. (2011). Scutellarin alleviates interstitial fibrosis and cardiac dysfunction of infarct rats by inhibiting TGFbeta1 expression and activation of p38-MAPK and ERK1/2. Br. J. Pharmacol. 162, 688-700. doi: 10.1111/j.1476-5381.2010.01070.x

Panchal, S. K., Poudyal, H., and Brown, L. (2012). Quercetin ameliorates cardiovascular, hepatic, and metabolic changes in diet-induced metabolic syndrome in rats. J. Nutr. 142, 1026-1032. doi: 10.3945/jn.111.157263

Parkar, N. A., Bhatt, L. K., and Addepalli, V. (2016). Efficacy of nobiletin, a citrus flavonoid, in the treatment of the cardiovascular dysfunction of diabetes in rats. Food Funct. 7, 3121-3129. doi: 10.1039/C6FO00294C

Pawlikowska-Pawlega, B., Gruszecki, W. I., Misiak, L. E., and Gawron, A. (2003). The study of the quercetin action on human erythrocyte membranes. Biochem. Pharmacol. 66, 605-612. doi: 10.1016/S0006-2952(03)00344-7

Prabhu, S. D., and Frangogiannis, N. G. (2016). The biological basis for cardiac repair after myocardial infarction: from inflammation to fibrosis. Circ. Res. 119, 91-112. doi: 10.1161/CIRCRESAHA.116.303577

Prathapan, A., Varghese, M. V., S, A., P, S. R., Mathew, A. K., Nair, A., et al. (2017). Polyphenol rich ethanolic extract from Boerhavia diffusa L. mitigates angiotensin II induced cardiac hypertrophy and fibrosis in rats. Biomed. Pharmacother. 87, 427-436. doi: 10.1016/j.biopha.2016.12.114
Qian, Y., Zhong, P., Liang, D., Xu, Z., Skibba, M., Zeng, C., et al. (2015). A newly designed curcumin analog Y20 mitigates cardiac injury via antiinflammatory and anti-oxidant actions in obese rats. PLoS ONE 10:e120215. doi: 10.1371/journal.pone.0120215

Qin, W., Du, N., Zhang, L., Wu, X., Hu, Y., Li, X., et al. (2015). Genistein alleviates pressure overload-induced cardiac dysfunction and interstitial fibrosis in mice. Br. J. Pharmacol. 172, 5559-5572. doi: 10.1111/bph.13002

Raj, P., Louis, X. L., Thandapilly, S. J., Movahed, A., Zieroth, S., and Netticadan, T. (2014). Potential of resveratrol in the treatment of heart failure. Life Sci. 95, 63-71. doi: 10.1016/j.lfs.2013.12.011

Ramirez-Sanchez, I., De los Santos, S., Gonzalez-Basurto, S., Canto, P., Mendoza-Lorenzo, P., Palma-Flores, C., et al. (2014). (-)-Epicatechin improves mitochondrial-related protein levels and ameliorates oxidative stress in dystrophic delta-sarcoglycan null mouse striated muscle. FEBS J. 281, 5567-5580. doi: 10.1111/febs.13098

Ramprasath, T., Senthamizharasi, M., Vasudevan, V., Sasikumar, S., Yuvaraj, S., and Selvam, G. S. (2014). Naringenin confers protection against oxidative stress through upregulation of Nrf2 target genes in cardiomyoblast cells. J. Physiol. Biochem. 70, 407-415. doi: 10.1007/s13105-014-0318-3

Rauf, A., Imran, M., Suleria, H. A. R., Ahmad, B., Peters, D. G., and Mubarak, M. S. (2017). A comprehensive review of the health perspectives of resveratrol. Food Funct. 8, 4284-4305. doi: 10.1039/C7FO01300K

Roche, P. L., Filomeno, K. L., Bagchi, R. A., and Czubryt, M. P. (2015). Intracellular signaling of cardiac fibroblasts. Compr. Physiol. 5, 721-760. doi: $10.1002 /$ cphy.c140044

Roohbakhsh, A., Parhiz, H., Soltani, F., Rezaee, R., and Iranshahi, M. (2015). Molecular mechanisms behind the biological effects of hesperidin and hesperetin for the prevention of cancer and cardiovascular diseases. Life Sci. 124, 64-74. doi: 10.1016/j.lfs.2014.12.030

Sadoshima, J., and Izumo, S. (1993). Molecular characterization of angiotensin II-induced hypertrophy of cardiac myocytes and hyperplasia of cardiac fibroblasts. critical role of the AT1 receptor subtype. Circ. Res. 73, 413-423. doi: 10.1161/01.RES.73.3.413

Salomone, F., Godos, J., and Zelber-Sagi, S. (2016). Natural antioxidants for nonalcoholic fatty liver disease: molecular targets and clinical perspectives. Liver Int. 36, 5-20. doi: 10.1111/liv.12975

Sarrazy, V., Koehler, A., Chow, M. L., Zimina, E., Li, C. X., Kato, H., et al. (2014). Integrins alphavbeta 5 and alphavbeta 3 promote latent TGF-betal activation by human cardiac fibroblast contraction. Cardiovasc. Res. 102, 407-417. doi: $10.1093 / \mathrm{cvr} / \mathrm{cvu} 053$

Schultz Jel, J., Witt, S. A., Glascock, B. J., Nieman, M. L., Reiser, P. J., Nix, S. L., et al. (2002). TGF-betal mediates the hypertrophic cardiomyocyte growth induced by angiotensin II. J. Clin. Invest. 109, 787-796. doi: 10.1172/JCI02 14190

Selvaraj, P., and Pugalendi, K. V. (2010). Hesperidin, a flavanone glycoside, on lipid peroxidation and antioxidant status in experimental myocardial ischemic rats. Redox Rep. 15, 217-223. doi: 10.1179/135100010X12826446921509

Shanmugam, P., Valente, A. J., Prabhu, S. D., Venkatesan, B., Yoshida, T., Delafontaine, P., et al. (2011). Angiotensin-II type 1 receptor and NOX2 mediate TCF/LEF and CREB dependent WISP1 induction and cardiomyocyte hypertrophy. J. Mol. Cell. Cardiol. 50, 928-938. doi: 10.1016/j.yjmcc.2011.02.012

Sheng, R., Gu, Z. L., Xie, M. L., Zhou, W. X., and Guo, C. Y. (2007). EGCG inhibits cardiomyocyte apoptosis in pressure overload-induced cardiac hypertrophy and protects cardiomyocytes from oxidative stress in rats. Acta Pharmacol. Sin. 28, 191-201. doi: 10.1111/j.1745-7254.2007.00495.x

Sheng, R., Gu, Z. L., Xie, M. L., Zhou, W. X., and Guo, C. Y. (2009). EGCG inhibits proliferation of cardiac fibroblasts in rats with cardiac hypertrophy. Planta Med. 75, 113-120. doi: 10.1055/s-0028-1088387

Škemiene, K., Jablonskiene, G., Liobikas, J., and Borutaite, V. (2013). Protecting the heart against ischemia/reperfusion-induced necrosis and apoptosis: the effect of anthocyanins. Medicina 49, 84-88.

Skemiene, K., Liobikas, J., and Borutaite, V. (2015). Anthocyanins as substrates for mitochondrial complex I - protective effect against heart ischemic injury. FEBS J. 282, 963-971. doi: 10.1111/febs.13195

Subburaman, S., Ganesan, K., and Ramachandran, M. (2014). Protective role of naringenin against doxorubicin-induced cardiotoxicity in a rat model: histopathology and mRNA expression 
profile studies. J. Environ. Pathol. Toxicol. Oncol. 33, 363-376. doi: 10.1615/JEnvironPatholToxicolOncol.2014010625

Sun, C. D., Zhang, B., Zhang, J. K., Xu, C. J., Wu, Y. L., Li, X., et al. (2012). Cyanidin-3-glucoside-rich extract from Chinese bayberry fruit protects pancreatic beta cells and ameliorates hyperglycemia in streptozotocininduced diabetic mice. J. Med. Food 15, 288-298. doi: 10.1089/jmf.2011. 1806

Sunagawa, Y., Morimoto, T., Wada, H., Takaya, T., Katanasaka, Y., Kawamura, T., et al. (2011). A natural p300-specific histone acetyltransferase inhibitor, curcumin, in addition to angiotensin-converting enzyme inhibitor, exerts beneficial effects on left ventricular systolic function after myocardial infarction in rats. Circ. J. 75, 2151-2159. doi: 10.1253/circj.CJ-1 $0-1072$

Sunagawa, Y., Sono, S., Katanasaka, Y., Funamoto, M., Hirano, S., Miyazaki, Y., et al. (2014). Optimal dose-setting study of curcumin for improvement of left ventricular systolic function after myocardial infarction in rats. J. Pharmacol. Sci. 126, 329-336. doi: 10.1254/jphs.14151FP

Sung, M. M., and Dyck, J. R. (2015). Therapeutic potential of resveratrol in heart failure. Ann. N.Y. Acad. Sci. 1348, 32-45. doi: 10.1111/nyas. 12839

Sung, M. M., Das, S. K., Levasseur, J., Byrne, N. J., Fung, D., Kim, T. T., et al. (2015). Resveratrol treatment of mice with pressure-overload-induced heart failure improves diastolic function and cardiac energy metabolism. Circ. Heart Fail. 8, 128-137. doi: 10.1161/CIRCHEARTFAILURE.114.001677

Suzuki, J., Ogawa, M., Futamatsu, H., Kosuge, H., Sagesaka, Y. M., and Isobe, M. (2007). Tea catechins improve left ventricular dysfunction, suppress myocardial inflammation and fibrosis, and alter cytokine expression in rat autoimmune myocarditis. Eur. J. Heart Fail. 9, 152-159. doi: 10.1016/j.ejheart.2006. 05.007

Travers, J. G., Kamal, F. A., Robbins, J., Yutzey, K. E., and Blaxall, B. C. (2016). Cardiac fibrosis: the fibroblast awakens. Circ. Res. 118, 1021-1040. doi: 10.1161/CIRCRESAHA.115.306565

Tsutsui, H., Kinugawa, S., and Matsushima, S. (2011). Oxidative stress and heart failure. Am. J. Physiol. Heart Circ. Physiol. 301, H2181-H2190. doi: 10.1152/ajpheart.00554.2011

Tuuminen, R., Nykanen, A. I., Krebs, R., Soronen, J., Pajusola, K., Keranen, M. A., et al. (2009). PDGF-A, -C, and -D but not PDGF-B increase TGF-betal and chronic rejection in rat cardiac allografts. Arterioscler. Thromb. Vasc. Biol. 29, 691-698. doi: 10.1161/ATVBAHA.108.178558

Um, J. H., Park, S. J., Kang, H., Yang, S., Foretz, M., McBurney, M. W., et al. (2010). AMP-activated protein kinase-deficient mice are resistant to the metabolic effects of resveratrol. Diabetes 59, 554-563. doi: 10.2337/db0 9-0482

Vaiyapuri, S., Ali, M. S., Moraes, L. A., Sage, T., Lewis, K. R., Jones, C. I., et al. (2013). Tangeretin regulates platelet function through inhibition of phosphoinositide 3-kinase and cyclic nucleotide signaling. Arterioscler. Thromb. Vasc. Biol. 33, 2740-2749. doi: 10.1161/ATVBAHA.113.301988

Van de Werf, F. (2014). The history of coronary reperfusion. Eur. Heart J. 35, 2510-2515. doi: 10.1093/eurheartj/ehu268

Wang, A. W., Song, L., Miao, J., Wang, H. X., Tian, C., Jiang, X., et al. (2015). Baicalein attenuates angiotensin II-induced cardiac remodeling via inhibition of AKT/mTOR, ERK1/2, NF-кB, and calcineurin signaling pathways in mice. Am. J. Hypertens. 28, 518-526. doi: 10.1093/ajh/hpu194

Wang, N. P., Wang, Z. F., Tootle, S., Philip, T., and Zhao, Z. Q. (2012). Curcumin promotes cardiac repair and ameliorates cardiac dysfunction following myocardial infarction. Br. J. Pharmacol. 167, 1550-1562. doi: 10.1111/j.1476-5381.2012.02109.x

Wang, T., Pan, D., Zhang, Y., Li, D., Zhang, Y., Xu, T., et al. (2015). Luteolin antagonizes angiotensin II-dependent proliferation and collagen synthesis of cultured rat cardiac fibroblasts. Curr. Pharm. Biotechnol. 16, 430-439. doi: 10.2174/1389201015666141110142402

Wang, Y., Wu, Y., Chen, J., Zhao, S., and Li, H. (2013). Pirfenidone attenuates cardiac fibrosis in a mouse model of TAC-induced left ventricular remodeling by suppressing NLRP3 inflammasome formation. Cardiology 126, 1-11. doi: $10.1159 / 000351179$

Wang, Y., Zhou, S., Sun, W., McClung, K., Pan, Y., Liang, G., et al. (2014). Inhibition of JNK by novel curcumin analog C66 prevents diabetic cardiomyopathy with a preservation of cardiac metallothionein expression. Am. J. Physiol. Endocrinol. Metab. 306, E1239-E1247. doi: 10.1152/ajpendo.00629.2013

Wu, H., Li, G. N., Xie, J., Li, R., Chen, Q. H., Chen, J. Z., et al. (2016). Resveratrol ameliorates myocardial fibrosis by inhibiting ROS/ERK/TGFbeta/periostin pathway in STZ-induced diabetic mice. BMC Cardiovasc. Disord. 16:5. doi: 10.1186/s12872-015-0169-Z

Wu, Q. Q., Xiao, Y., Jiang, X. H., Yuan, Y., Yang, Z., Chang, W., et al. (2017a). Evodiamine attenuates TGF-betal-induced fibroblast activation and endothelial to mesenchymal transition. Mol. Cell. Biochem. 430, 81-90. doi: 10.1007/s11010-017-2956-6

Wu, Q. Q., Xiao, Y., Yuan, Y., Ma, Z. G., Liao, H. H., Liu, C., et al. (2017b). Mechanisms contributing to cardiac remodelling. Clin. Sci. 131, 2319-2345. doi: $10.1042 / C S 20171167$

Wynn, T. A. (2008). Cellular and molecular mechanisms of fibrosis. J. Pathol. 214, 199-210. doi: 10.1002/path.2277

Xiao, J., Sheng, X., Zhang, X., Guo, M., and Ji, X. (2016). Curcumin protects against myocardial infarction-induced cardiac fibrosis via SIRT1 activation in vivo and in vitro. Drug Des. Devel. Ther. 10, 1267-1277. doi: 10.2147/DDDT.S 104925

Yan, W., Wang, P., Zhao, C. X., Tang, J., Xiao, X., and Wang, D. W. (2009). Decorin gene delivery inhibits cardiac fibrosis in spontaneously hypertensive rats by modulation of transforming growth factor-beta/Smad and p38 mitogenactivated protein kinase signaling pathways. Hum. Gene Ther. 20, 1190-1200. doi: 10.1089/hum.2008.204

Yang, Z., Liu, Y., Deng, W., Dai, J., Li, F., Yuan, Y., et al. (2014). Hesperetin attenuates mitochondria-dependent apoptosis in lipopolysaccharideinduced H9C2 cardiomyocytes. Mol. Med. Rep. 9, 1941-1946. doi: 10.3892/mmr.2014.2002

You, Q., Wu, Z., Wu, B., Liu, C., Huang, R., Yang, L., et al. (2016). Naringin protects cardiomyocytes against hyperglycemia-induced injuries in vitro and in vivo. J. Endocrinol. 230, 197-214. doi: 10.1530/JOE-16-0004

Yu, W., Wu, J., Cai, F., Xiang, J., Zha, W., Fan, D., et al. (2012). Curcumin alleviates diabetic cardiomyopathy in experimental diabetic rats. PLoS ONE 7:e52013. doi: 10.1371/journal.pone.0052013

Zannad, F., Alla, F., Dousset, B., Perez, A., and Pitt, B. (2000). Limitation of excessive extracellular matrix turnover may contribute to survival benefit of spironolactone therapy in patients with congestive heart failure: insights from the randomized aldactone evaluation study (RALES). rales investigators. Circulation 102, 2700-2706. doi: 10.1161/01.CIR.102.2 2.2700

Zeng, C., Zhong, P., Zhao, Y., Kanchana, K., Zhang, Y., Khan, Z. A., et al. (2015). Curcumin protects hearts from FFA-induced injury by activating Nrf2 and inactivating NF-кB both in vitro and in vivo. J. Mol. Cell. Cardiol. 79, 1-12. doi: 10.1016/j.yjmcc.2014.10.002

Zhang, N., Yang, Z., Xiang, S. Z., Jin, Y. G., Wei, W. Y., Bian, Z. Y., et al. (2016). Nobiletin attenuates cardiac dysfunction, oxidative stress, and inflammatory in streptozotocin: induced diabetic cardiomyopathy. Mol. Cell. Biochem. 417, 87-96. doi: 10.1007/s11010-016-2716-Z

Zhang, N., Yang, Z., Yuan, Y., Li, F., Liu, Y., Ma, Z., et al. (2015). Naringenin attenuates pressure overload-induced cardiac hypertrophy. Exp. Ther. Med. 10, 2206-2212. doi: 10.3892/etm.2015.2816

Zhang, Y., Mi, S. L., Hu, N., Doser, T. A., Sun, A., Ge, J., et al. (2014). Mitochondrial aldehyde dehydrogenase 2 accentuates aging-induced cardiac remodeling and contractile dysfunction: role of AMPK, Sirt1, and mitochondrial function. Free Radic. Biol. Med. 71, 208-220. doi: 10.1016/j.freeradbiomed.2014. 03.018

Zhao, F., Fu, L., Yang, W., Dong, Y., Yang, J., Sun, S., et al. (2016). Cardioprotective effects of baicalein on heart failure via modulation of $\mathrm{Ca}(2+)$ handling proteins in vivo and in vitro. Life Sci. 145, 213-223. doi: 10.1016/j.lfs.2015. 12.036

Zhao, T., Zhao, W., Chen, Y., Li, V. S., Meng, W., and Sun, Y. (2013). Platelet-derived growth factor-D promotes fibrogenesis of cardiac fibroblasts. Am. J. Physiol. Heart Circ. Physiol. 304, H1719-H1726. doi: 10.1152/ajpheart.00130.2013

Zhou, H., Chen, X., Chen, L., Zhou, X., Zheng, G., Zhang, H., et al. (2014). Anti-fibrosis effect of scutellarin via inhibition of endothelial-mesenchymal transition on isoprenaline-induced myocardial fibrosis in rats. Molecules 19, 15611-15623. doi: 10.3390/molecules 191015611 
Zhu, Z. Y., Gao, T., Huang, Y., Xue, J., and Xie, M. L. (2016). Apigenin ameliorates hypertension-induced cardiac hypertrophy and down-regulates cardiac hypoxia inducible factor-lalpha in rats. Food Funct. 7, 1992-1998. doi: 10.1039/C5FO01464F

Zong, J., Zhang, D. P., Zhou, H., Bian, Z. Y., Deng, W., Dai, J., et al. (2013). Baicalein protects against cardiac hypertrophy through blocking MEK-ERK1/2 signaling. J. Cell. Biochem. 114, 1058-1065. doi: 10.1002/jcb.24445

Zordoky, B. N., Robertson, I. M., and Dyck, J. R. (2015). Preclinical and clinical evidence for the role of resveratrol in the treatment of cardiovascular diseases. Biochim. Biophys. Acta 1852, 1155-1177. doi: 10.1016/j.bbadis.2014. 10.016
Conflict of Interest Statement: The authors declare that the research was conducted in the absence of any commercial or financial relationships that could be construed as a potential conflict of interest.

Copyright (๔ 2018 Zhang, Wei, Li, Hu and Tang. This is an open-access article distributed under the terms of the Creative Commons Attribution License (CC $B Y)$. The use, distribution or reproduction in other forums is permitted, provided the original author(s) and the copyright owner are credited and that the original publication in this journal is cited, in accordance with accepted academic practice. No use, distribution or reproduction is permitted which does not comply with these terms. 